\title{
Success of Community Management Based on the Collaboration: Lesson Learned for Environmental Crisis Solutions
}

\author{
Nathdanai Pratuangboriboon \\ Faculty of Humanities and Social Sciences \\ Lampang Rajabhat University, Thailand \\ nathdanaipg@gmail.com
}

\begin{abstract}
World change influences the changes in the economy, society, environment, way of life, culture, and traditions into slavery of capitalism, materialism, and consumerisms including modern trends all have a great impact on the country's development. This is why "Society has problems and the development is not sustainable" while Ban Thung Sri Community, Moo 3, Thung Sri Subdistrict, Rong Kwang district, Phrae province, Thailand has been accredited by various institutions in community management in a variety of dimensions until the community is successful. When the study was conducted, the Lesson learned of community management for environmental crisis solutions, which the community believes is a sustainable solution to the environmental crisis and driven by community strategies. This can be an example that other communities can apply concretely. KEYWORDS: Community Management, Collaboration, Environmental Crisis Solutions
\end{abstract}

\section{Introduction}

World change impacts on the economy, society, environment, lifestyle, culture, traditions, rituals, and beliefs as well as good things. Lack of connection is a crisis 
that most communities are facing. Many communities have collapsed because of the development of new forms, destroying the traditional foundations. (Naowavathong et. al. 2008). Thailand is likely to receive culture and prosperity in science and technology from the foreign countries to develop the country more and more respectively. It can be said that Thai society today is dominated by Western ideas and wisdom. It is a slave to capitalism, materialism and consumerism and modern trends that comes from the Western world and has a global influence which causes social problems. The economy and the environment are inevitable with the situations around the world are changing fast. These have all contributed to the country's development in every way. This is why "Society has problems and the development is not sustainable" (Kamolpratuengkorn 2016). Capitalism has also resulted in rapid change and caused the living of the people to be more comfortable. The development of this approach also affects the well-being of people in all levels of society, including cultural decline, lack of good relationship, and the values of living in luxuries in the consumer society. Moreover, family and community institutions are weak and cause many social problems (Wongsrikaew et al. 2556).

However, the development of the country to sustainable balance from The 10th National Economic and Social Development Plan in Strategy 2 states that priority is given to strengthen existing capital both the social capital, economic capital and the resources of natural resources and the environment to be more and more linked to the development. The social capital building will be the main basis. It is needed to start from the quality of people to have a moral with public consciousness and knowledge of change leading to strong community development, mutual support within the community and between communities and the power of the country. The community can manage and utilize economic capital, social capital, natural resources capital, and environment in a balanced way, in harmony with the traditions and culture of the community in order to strengthen the social intimacy between people inside and outside the community. According to the strong integration of people in the community, in addition to the ability to prevent and solve difficult and complex problems, while community management refers to the creation of process science and the action to the village or community that has the knowledge to manage their own community by using a powerful community plan as a development tool following the process of community empowerment (Naowavathong et al. 2008)

One of the interesting communities is Ban Thung Sri Moo 3, Thung Sri Sub-district, Rong Kwang district, Phrae province, which is accredited by various institutions for community management in a variety of dimensions until successful. For example, being a prototype community for local solid waste management. There are administrators, 
community leaders, involved officials and people participate in community solid waste management which won the first runner-up in the tropical program reducing the heat by our hands organized by the Environmental Institute Foundation and Toyota Motor (Thailand) Co., Ltd. In the year 2014 Ban Thung Sri Moo 3 was awarded the village of non-burning prototype to fight the northern fog from the Department of Environmental Quality Promotion. In the year 2012 the community was awarded the first winner of the 80th Annual 80th Community for Waste Recycle Contest organized by the Department of Environmental Quality, Ministry of Natural Resources and Environment. Moreover, there are also projects at Ban Thung Sri Community, such as Organic fertilizer / compost from local raw materials, the project of agricultural tourism and integrated waste management, establishment of community culture centers and folk museums, the promotion of the use of bio-organic fertilizers and the reduction of the use of chemical fertilizers in agriculture, project for setting up savings enterprise for organic fertilizer production, Community Waste Fund Project, Spa project with earthworms. These are the use of waste more and more.

Therefore, the researcher is interested to take the community management lesson to solve the environmental crisis to find the factors that affect the success of community organization and lead to the prototype community of Ban Thung Sri Moo 3, Thung Si Sub-district, Rong Kwang district, Phrae province.

\section{Research Objectives}

1. To disseminate the success stories of communities in solving the environmental crisis that led to the prototype community of Ban Thung Sri Moo 3, Thung Sri Subdistrict, Rong Kwang district, Phrae Province.

2. To propose a community management model to solve the underlying environmental crisis of Ban Thung Sri Moo 3, Tung Sri Sub-district, Rong Kwang district, Phrae province.

\section{Research Methodology}

The research was designed using qualitative research by 1) studying and analyzing data from secondary sources. 2) Field research to obtain primary data by in-depth interview to find answers to the differences in opinions. The interviewees were interviewed by the researchers. The interviews were conducted in the form of unstructured interviews consisted of provincial administrators and district administrators. Local leaders were the mayor of Rong Kwang District Municipality, Sub-district Headman of Thung 58 
Sri Sub-district, Village Headman, Village Committee and people in the village of Thung Sri Moo 3, Thung sri Sub-district, Rong Kwang district in Phrae province total 30 people. Data were analyzed the results to discuss the implications of the concepts and the related research by analyzing content and presenting it in a descriptive way.

\section{Research result}

The context of Ban Thung Sri Moo 3, Thung Sri Sub-district, Rong Kwang district, Phrae province originally, the regime used the common system. There was water management by the marshal system. The leader of the mines will be the leader in all aspects because he had been chosen from the person who is knowledgeable both way of life in the world and Buddhism. Be fair and Dhamma is a main of fellowship. Thung Sri Temple is the center of the meeting with a total of 376 people. There are 114 households. The majority of the populations is agriculturists for 66 families. At present, some villagers go to work in other communities and bring the culture of extravagance to the community. Young people began to have the social trend according to current tastes society. In addition, there is also a lack of pride in the value of local wisdom. There is also a continued migration to work which causes labor shortage in the community. The current problem is that the water source for agriculture is not enough, high cost of production, shortage of markets for agricultural products, pesticide residues from agriculture, income is not balanced with expenditure. Moreover, there are no secondary and supplementary occupations. There are no documents in the land, health problems with toxic residues in the body, and does not care about health care.

The results of the study revealed that Ban Thung Sri had a process of starting from thinking together between leaders and people in the community. In the beginning there were only 10 people whom this group called themselves. "Good Promoters" talked about problems in the community. This is a problem caused by increased waste. While local communities and local organizations are not able to effectively manage their living and the change in society has made people in the community more comfortable living by buying other consumer goods into the community. This causes garbage problem in the community. Beyond the issue of garbage, the Good Promoters also brought other problems occurred in the community to participate in the discussion. The smog problems caused by burning the remaining produce from agriculture, burning weeds, and burning waste have caused pollution in the community. There are health problems caused by the use of chemicals in the production and consumption. It causes chemical residues in agricultural products in soil, water and air, as well as chemical accumulation 
in the community environment. The problems that occur also affect the quality of life in the community. In the economy, the income of the people in the community is not enough for living. They borrow and have the debt causing the household have debt. In society, people in the community lack of love and harmony, ignore each other because life must survive to ignore the people around. Not accepting the opinions of people in the community with each other cause of conflict and social disparity of the community. This is because the income level of the people in the community is different. While the problem occurred it also directly affects the environment of the community. That creates a critical environment and the community is unlikely to live. Discussion of the Good Promoters is the brainstorm to solve community problems with the initial talk of a few people. The basic idea is that to solve problems one at a time may not permanently solve community problems. It is based on the holistic view to solve the problem. In the beginning, the Good Promoters will spend a lot of time talking about issues and resolving community problems and think that the people in the community should participate in the comments. Therefore, the group has provided a place to be a meeting place of the community. It is a gesture of confidence in the community that community collaboration can solve problems tangibly. After having the meeting place, the Good Promoters have shown the community a common problem. There are many obstacles to solve the problem. Only people in the community cannot solve the problem so it should be based outside the community such as the government sector, educational institution, and network partners for creating the learning process to take place in the community by training and collecting data both the original knowledge existing in the community and new interdisciplinary knowledge are integrated and continuous to prevent disruptions.

Learning will focus on the problem of community to make a plan to solve community problems. The plan includes: Experimentation, improvement, and extension such as organic vegetables, biological fertilizer, worm fertilizer, et cetera. The problem is to learn to plan the community. It is a solution to the problems of the community. The community of Thung Sri has set goals to solve problems in order to reduce inequality, reduce the conflict of people in the community, and back to the natural way. The solution to the problem is to cultivate and create public consciousness for people in the community to see the importance of others and the suffering of the community to raise awareness of problems, find solutions to common problems together and create the benefits, use benefits and receive benefits of sharing in the community.

However, solving the problems of Ban Thung Sri Community will be concrete and consistent. It is important to define a community strategy with the process of community collaboration to be the direction to fix and develop with the management 
of their own community. In addition, the community also needs to have some support from outside the community to help and support. Then the community can be successfully driven. The case of Ban Thung Sri determined the vision of the community is "Community management systematically leading to the excellent agriculture". The target is that the people in the community have good health, good household and community economy, and the community environment is good. The results of the study can be written as a community management model to solve the environmental crisis prototype of Ban Thung Sri Moo 3, Thung Sri Sub-district, Rong Kwang district, Phrae province, as shown below.

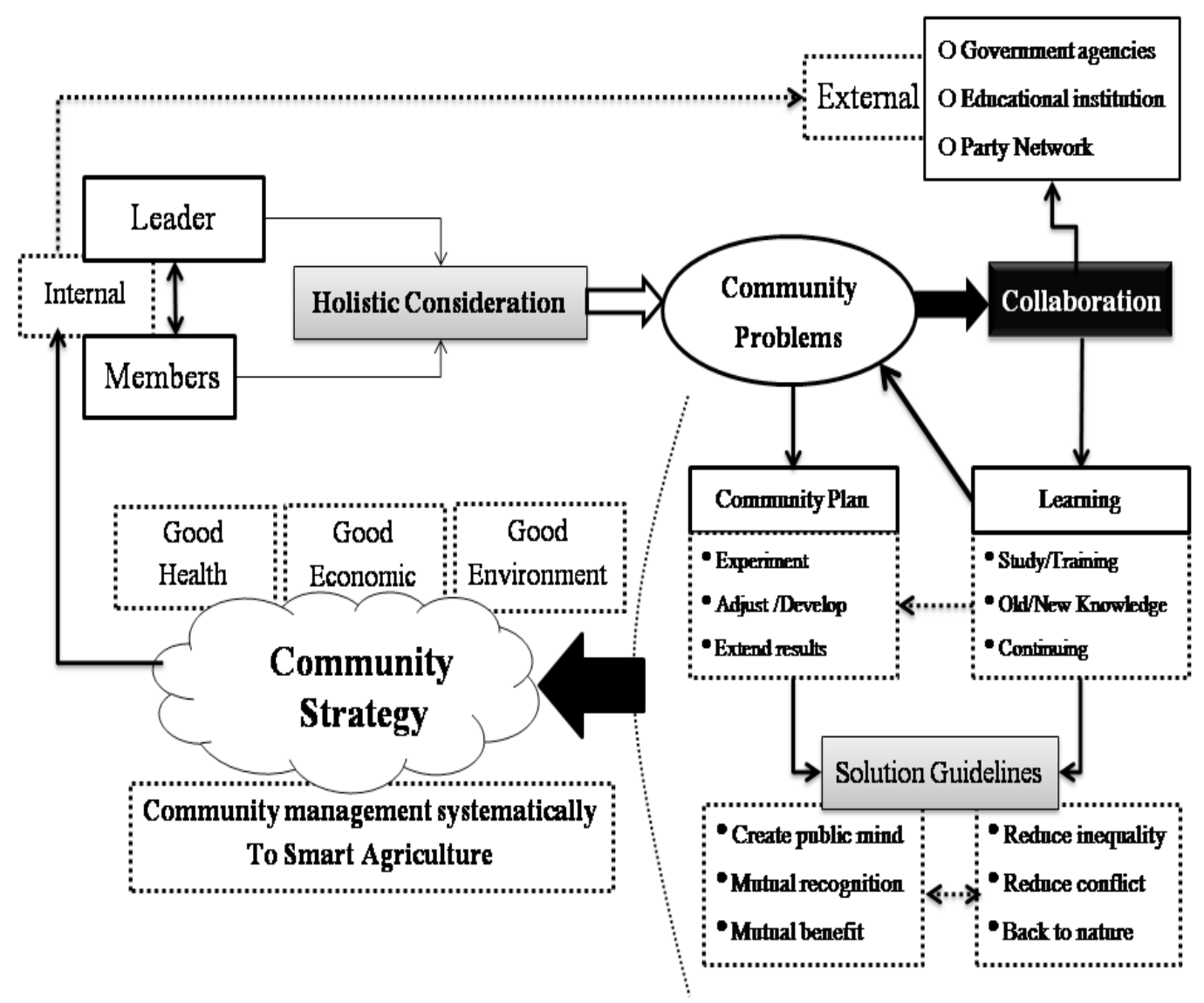

Figure 1. Lesson learned of community management for environmental crisis solutions of BanThungsri, Moo 3 Thungsri Sub-district, RongKwuang District, Phrae Province. 
At present, Ban Thung Sri Moo 3, Thung Sri Sub-district, Rong Kwang District, Phrae Province, the community management was initiated by the combination of people in the village and between the villages at the district level and provincial level to strengthen the community to think about learning to practice. There is the process of learning and knowledge management in a variety of ways. This is a good way to live up to the wisdom and culture of the community with prudence and discretion. There is virtue, morality, love, generosity, harmony, selflessness, commitment to develop self and others. It is the invocation of the philosophy of sufficiency economy of King Bhumibol Adulyadej of the Thai people. This is the main activity of the people in the community from the beginning, "Explosion from inside" to seek solutions to move to a happy balance and self-reliant. The community can manage and utilize social capital from the existing natural and environmental resources that are linked to the traditions and culture of the community. The strong combination of people in the community can prevent and solve difficult and complex problems. It also helps the community to develop the future of the community following the strategy of strengthening the community and society to be a solid foundation of the country.

\section{Conclusions}

The results of the study found that the holistic approach to problem solving can solve the problem of community permanently. It is consistent with Mahidol University (2011), which states that synthetic thinking to look at the holistic image as a new concept or concept frame through a systematic thinking process capable of understanding the relationship between things that is an important element of the system. As a result of the pattern summary applying a variety of scenarios or situations, or multiple perspectives, in an overview of the community, the problem elements, and cause of problem, this will lead to the concept of a concrete solution. While managing on a cooperative basis is an important element in driving the community's problemsolving to goal concretely because the collaboration creates a different perspective through the learning process. Incorporation of existing knowledge into the community with new knowledge gained from outside the community through experimentation, improvement, and extension are the creation of success both short term and longterm in accordance with the National Assembly of National Voluntary Health \& Social Welfare Organization (1997). It is a formal process which is committed to working together in the long term toward the crisis-related mission or important and complex social issues. This is a joint decision and resource allocation through performance activities to meet the common needs. It is also consistent with Brown. 
A.D. (2006), a specialist in collaborative research at the University of North Carolina, has identified two goals for work and collaboration: 1) Short-term cooperation is a collaborative process that works together to solve the facing problems immediately. 2) Long-term cooperation is a collaborative process that is used when developing or changing things. The partnership must continue to be sustainable, as Hutchings. P., et al. (2017) state that community management widely criticized, but the concept of community management is still important in modern management to adapt to the increasing demand. External support agencies must be ready to accommodate more and more ongoing support in order to lead to the success of the community.

Ban Thung Sri, Moo 3, Rong Kwang District, Phrae Province, has set the solution to the problem of reducing the economic disparity and to reduce the conflict of community members, and return to the basis of living with nature to make members have a good idea and think for the collective, awareness of problems and solutions. It is consistent with Pratuangboriboon. N. (2017) who states that the importance given to people in the community from individual, group and latent populations together with network partners, organization / agency both public and private sectors in the area creating norms of a community through collaborative design, make people learn in the community to develop the potential of the person, Organization / Club / Party to create a practice plan, operational guidelines, agreements or rules for all parties acknowledge and act appropriately in accordance with the duty of good citizens of society. This will increase the chance of problem management and reinforce the work in various tasks to achieve the goal.

However, the success of community management is critical to establishing a community strategy. The strategy is to lead the way to achieve the goal accurately and the thought of sharing from the members. The vision is clear with targeted objectives and missions that demonstrate community driven approaches to be true through the process of analyzing weaknesses, strengths, opportunities and barriers of the community, as Akaraborworn. C. et al. (2009) described that strategic planning is the methodology used as a measure of performance in various aspects. It represents the vision, mission, and purpose in order to be aware of and understand in the same direction. A system that monitors the success of a strategy by measuring performance for the right decision adjust to work to help to learn what strategies are available, how to achieve the mission and respond to the benefits of the communit. Haeberling F. (2009) states that the local community is about encouraging and supporting the community leading to growth by all members have the opportunity to comment on what is going on in their community. It is an important way of presenting the vision of the community as defined in the strategy. Ban Thung Sri, Moo 3, Rong Kwang District, Phrae province 
has set the vision of community as "Community Management Systematically to Smart Agriculture", which aims to provide the community to have good economy, community members have good health and good environment. The community believes that the mentioned strategy is a sustainable solution to the environmental crisis.

\section{Suggestion}

1. Other community should bring Lesson learned of community management for environmental crisis solutions of Ban Thung Sri, moo 3 Thung Sri Sub-district, Rong Kwuang District, Phrae Province apply to consider differences in the context of the community.

2. It should be learned from other successful communities in community management for comparison, composition analysis, and the factors that lead to the success of the community. This is a new knowledge to solve the environmental sustainability of the community.

\section{References}

Akaraborworn. C. and Charoensak. R. 2009. Strategic Map. Bangkok: Office of the Public Sector Development Commission ( OPDC ), pp.11-12.

Brown. A. D. 2006. "A Narrative Approach to Collective Identities." Journal of Management Studies 43(4):731-753.

Haeberling. F. 2009. The Sustainable Community Strategy 2009-2026, Making Bath \& North East Somerset an even better place, to live work and visit. England.

Hutchings. P., Franceys. R., Mekala. S., Smits. S. and A. J. James. 2017."Revisiting the history, concepts and typologies of community management for rural drinking water supply in India." International Journal of Water Resources Development 33(1):152-169.

Kamolpratuengkorn. K. 2016. "The Management of a Strong Community According to a Buddhist Way." Mahachulalongkornrajavidyalaya University. Journal of Graduate Studies Periscope 12(3):94-107.

Mahidol University. 2011. Definitions and details of management competencies. (Managerial Competency). Bangkok: Mahidol University, pp. 1-11.

Naowavathong. P. and Suppadit. T. 2008. "Sufficiency Economy - Community Management: A Case Study of Kham Pla Lai Village, Tambol Ban Dong, Amphur Ubonrat, Khon Kaen Province." National Institute of Development Administration. Journal of Environmental Management 4(2): 38-49. 
Pratuangboriboon. N. 2017."Koh-Kha Model: The Strategy for Balanced Local Administration in the Twenty-First Century." Journal of Graduate Studies in Northern Rajabhat University $7(12): 15-28$.

The National Assembly of National Voluntary Health \& Social Welfare Organizaton. 1997. The new Community Collaboration manual. (3th printing.). Washington, DC: Author

Wongsrikaew.K., Ruanggoon.J. and Chunprasert.C.2017. Development of Strong Community:A Case Study of Poonbumphen Community, Phasi Charoen District, Bangkok. DOI: 10.14456/j-com-dev-and-life-qua.2017.5. 